\title{
Pengaruh Aplikasi IAA pada Kecepatan Tumbuh Bibit Bud Chip Tebu (Saccharum officinarum L.) di Persemaian Pottray
}

\section{(The Effect of IAA Application on Germination Speed of Bud Chip Sugarcane [Saccharum officinarum L.] in a Pottray Nursery)}

\author{
Sigit Eko Prasetyo ${ }^{1)^{*}}$, Wiwik Indrawati ${ }^{2)}$, Made Same ${ }^{2)}$ \\ 1) Program Studi Produksi dan Manajemen Industri Perkebunan, Jurusan Budidaya Tanaman \\ Perkebunan, Politeknik Negeri Lampung, Jl. Soekarno-Hatta No.10 Rajabasa, Bandar Lampung, \\ Telp.: (0721) 703995 Fax.: (0721) 787309, ${ }^{2)}$ Jurusan Budidaya Tanaman Perkebunan, Politeknik \\ Negeri Lampung, Jl. Soekarno-Hatta No.10 Rajabasa, Bandar Lampung, Telp.: (0721) 703995 \\ Fax.: (0721) 787309 \\ E-mail : sigitekoprasetyo20@gmail.com
}

\begin{abstract}
This study was conducted at the Politeknik Negeri Lampung in December to February 2019. The research used factorial Randomized Block Design (RBD) with two factor and three replication. The first factor is the source of bud chip derived from the 3 part: $B_{1}$ (top), $B_{2}$ (middle), $B_{3}$ (bottom) and the second factor is the concentration of IAA with 4 levels of $A_{0}\left(0 \mathrm{mg} . l^{-1}\right), A_{l}\left(150 \mathrm{mg} . l^{-1}\right), A_{2}\left(300 \mathrm{mg} . l^{-1}\right)$, and $A_{3}\left(450 \mathrm{mg} . l^{-1}\right)$. The observed variable is speed of growing eye buds, percentage of growing buds, height of the plant, number of leaves, and diameter of stem. The results of study showed the origin of bud chip seed middle part has the best growth of variable speed grow, precentage of growth, high seeding, number of leaves, and diameter of the stem. IAA administration at concentrations $0-450 \mathrm{mg} . l^{-1}$ which has been applied to the source of bud chip upper, middle, and lower with immersion treatment for 20 minutes does not give a noticeable impact on the growing speed, precentage of growing, height plant, number of leaves, diameter of stem. There is no interaction between the origin of bud chip seed (top, middle, bottom) and IAA concentration.
\end{abstract}

Keywords: auxin, pottray, sugarcane, vegetative growth

DOI: http://dx.doi.org/10.25181/jaip.v8i2.1391

Diterima: 16 Oktober 2019 / Disetujui: 2 Agustus 2020 / Diterbitkan: 25 Oktober 2020

\section{PENDAHULUAN}

Tanaman tebu (Saccharum officinarum L.) ialah komoditas penting sebagai bahan baku pembuatan gula. Hal ini karena dalam batang tebu terkandung 20\% cairan gula. Seiring dengan peningkatan jumlah penduduk Indonesia, kebutuhan gula terus mengalami peningkatan, tetapi peningkatan belum dimbangi produksi gula dalam negeri sebagai akibat semakin sempitnya luas areal pertanaman tebu. Dalam beberapa tahun mendatang diperkirakan permintaan gula dalam negeri akan terus meningkat (Adinugraha, Nugroho, \& Wicaksono, 2016). 
Banyaknya produk yang membutuhkan gula sebagai bahan baku dalam sektor agroindustri mengakibatkan permintaan akan komoditas tebu juga terus meningkat sehingga terjadinya defisit gula. Defisit gula Indonesia untuk memenuhi kebutuhan konsumsi gula nasional mulai dirasakan sejak tahun 1967. Defisit ini terus meningkat dan hanya bisa dipenuhi melalui impor gula. Harga gula dunia yang tinggi dan defisit yang terus meningkat mengakibatkan terjadinya pengurangan devisa negara. Untuk mengatasi hal ini telah dilakukan berbagai usaha peningkatan produksi gula nasional (Indrawanto et al., 2010). Produksi gula dalam negeri 2016-2017 hanya mencapai 2,332 juta ton, produksi gula dalam negeri terbukti mengalami penurunan cukup jauh yang sebelumnya pada tahun 2010-2011 produksi gula dalam negeri mencapai 3,159 juta ton dengan luas pertanaman tebu 473.923 ha (Badan Pusat Statistik, 2017). Untuk mengatasi hal ini telah dilakukan usaha peningkatan produksi gula nasional. Salah satu cara untuk meningkatkan produktivitas tanaman tebu adalah dengan menyediakan bibit yang berkualitas. Hal ini dikarenakan bibit memiliki peran besar dalam produksi gula. Ketersediaan bibit tanam (bibit) yang memiliki tingkat pertumbuhan yang baik, ketahanan terhadap serangan hama dan penyakit tanaman serta memiliki tingkat rendemen gula yang tinggi akan mendukung peningkatan produksi gula. Menurut (Brilliyana et al., 2017) untuk memenuhi kebutuhan bibit dapat dilakukan dengan sistem bud chip. Pembibitan tebu bud chip merupakan langkah maju pada penerapan program bongkar ratoon, yaitu membongkar tanaman tebu yang sudah tiga kali kepras (panen) atau lebih, yang dinilai produktivitasnya makin menurun. Teknik pembibitan yang bisa menghasilkan bibit yang berkualitas serta tidak membutuhkan ketersediaan lahan yang luas adalah dengan teknik pembibitan bud chip (Yulianingtyas, Sebayang, \& Tyasmoro, 2015). Dezjona, Sudiarso, \& Islami (2013) menyatakan bahwa teknik pembibitan bud chip adalah teknik pembibitan tebu secara vegetatif yang menggunakan bibit satu mata.

Pottray merupakan wadah untuk tanaman yang berbentuk persegi panjang dan terbuat dari plastik yang tersusun atas beberapa lubang tanam (Situmeang, Barus, \& Irsal, 2015). Pottray biasa digunakan sebagai wadah sementara bibit tanaman sebelum dipindahtanamkan ke lahan permanen. Penggunaan bibit yang lebih efisien juga harus diimbangi dengan kecepatan pertumbuhannya maka dari itu digunakanlah auksin, yang merupakan hormon tumbuh yang tidak terlepas dari proses pertumbuhan dan perkembangan tanaman, salah satu jenis auksin yang besar peranannya yaiutu indole acetate acid (IAA). IAA merupakan jenis auksin yang berfungsi sebagai hormon pengembang sel yang struktur kimianya mirip asam amino triptofan, selain itu IAA juga berperan dalam pertumbuhan awal akar dan meningkatkan jumlah akar serabut.

Berdasarkan penelitian sebelumnya yang dilakukan Selvia, Meiriani, \& Hasanah (2015) juga menunjukan bahwa bibit bud chip terbaik diperoleh pada lama perendaman 20 menit, oleh karena itu penggunaan IAA diharapkan meningkatkan percepatan pertumbuhan bibit bud chip yang berasal dari mata tunas tebu bagian atas, tengah, dan bawah dengan perendaman ZPT IAA pada berbagai konsentrasi. 


\section{METODE PENELITIAN}

Penelitian ini dilakukan di kebun percobaan Politeknik Negeri Lampung selama 3 bulan sejak Desember 2018 hingga Februari 2019. Bahan yang digunakan dalam penelitian ini antara lain tebu varietas F5, ZPT IAA, tanah bagian lapisan atas (top soil), pasir, dan fungisida. Alat yang digunakan dalam penelitian ini adalah pottray dengan ukuran lubang atas $4 \mathrm{~cm} \times 4 \mathrm{~cm}$, lubang bawah 2,5 $\mathrm{cm}$ x 2,5 cm dengan tinggi $9 \mathrm{~cm}$ (dimensi pottray $27,5 \mathrm{~cm}$ x $36,6 \mathrm{~cm}$ x $9 \mathrm{~cm}$ dengan isi 45 lubang), golok, parang, penggaris, meteran, gelas ukur, kamera, jangka sorong, label, plakat nama, timbangan analitik, gembor, ember, dan alat tulis.

Penelitian ini menggunakan Rancangan acak kelompok (RAK) faktorial. Faktor pertama adalah 3 bagian bibit bud chip, yaitu: bagian bud chip atas $\left(\mathrm{B}_{1}\right)$, bagian bibit bud chip tengah $\left(\mathrm{B}_{2}\right)$, dan bagian bibit bud chip bawah $\left(\mathrm{B}_{3}\right)$. Faktor kedua adalah konsentrasi ZPT IAA, yaitu: 0 mg. $\mathrm{l}^{-1}$ $\left(\mathrm{A}_{0}\right), 150 \mathrm{mg} \cdot \mathrm{l}^{-1}\left(\mathrm{~A}_{1}\right), 300 \mathrm{mg} \cdot \mathrm{l}^{-1}\left(\mathrm{~A}_{2}\right)$, dan $450 \mathrm{mg} \cdot \mathrm{l}^{-1}\left(\mathrm{~A}_{3}\right)$.

Pelaksanaan penelitian meliputi persiapan media tanam, persiapan bedengan, persiapan bibit bud chip, pengisisan pottray, penanaman, pemeliharaan di pottray meliputi penyiraman dan penyiangan. Variabel yang diamati adalah kecepatan tumbuh mata tunas, persentase tumbuh tunas, tinggi bibit, jumlah daun dan diameter pelepah. Data dianalisis dengan sidik ragam dengan taraf alpha 5\%, apabila terdapat beda nyata (F hitung > F tabel 5\%) dilanjutkan dengan uji BNT.

\section{HASIL DAN PEMBAHASAN}

\section{Kecepatan Tumbuh Bud Chip}

Berdasarkan hasil sidik ragam diketahui bahwa perlakuan sumber bud chip berpengaruh nyata terhadap parameter kecepatan tumbuh mata tunas pada umur 2-7 hari setelah tanam (HST), sedangkan aplikasi IAA dan interaksi antara keduanya berpengaruh tidak nyata (Tabel 1). Kecepatan tumbuh mata tunas yang berasal dari sumber bud chip bagian atas dan tengah berpengaruh nyata pada variabel pengamatan kecepatan tumbuh karena sumber bud chip bagian tengah memiliki pertumbuhan yang lebih baik daripada sumber bud chip bagian atas dan bawah. Pengaruh ini diduga karena bud chip yang berasal dari batang tengah memiliki daya berkecambah yang cepat karena didukung oleh tunas-tunas yang relatif lebih muda serta mudah dalam pemecahan dormansi. Hasil ini didukung oleh Iwan, Bambang, \& Ubud (2014) yang menyatakan bahwa mata tunas pada batang bawah tanaman tebu telah mengalami penuaan dan kerusakan yang menyebabkan rendahnya persentase perkecambahan pada awal penanaman.

Sumber bud chip bagian tengah umur 7 HST yang memiliki pertumbuhan lebih baik daripada sumber bud chip bagian atas dan bawah diduga sumber bud chip bagian tengah memiliki kandungan asam amino dan karbohidrat yang seimbang. Selain dari segi penuaan tunas batang 
bagian atas juga memiliki banyak tunas dan pasokan nutrisi yang baik sehingga membuat batang bagian atas memiliki pertumbuhan yang cukup baik.

Tabel 1. Kecepatan tumbuh tunas bibit bud chip pada umur 2-7 HST

\begin{tabular}{cccccccc}
\hline \multirow{2}{*}{ Perlakuan } & \multicolumn{7}{c}{ Waktu pengamatan } \\
\cline { 2 - 8 } & 2 & HST & 3 HST & 4 HST & $5 \mathrm{HST}$ & $6 \mathrm{HST}$ & 7 HST \\
\hline \multirow{2}{*}{$\begin{array}{c}\text { Sumber Bud } \\
\text { chip }\end{array}$} & Tengah & $0,00 \mathrm{a}$ & $1,33 \mathrm{~b}$ & $1,78 \mathrm{a}$ & $2,11 \mathrm{a}$ & $2,44 \mathrm{a}$ & $2,44 \mathrm{~b}$ \\
& Bawah & $0,11 \mathrm{c}$ & $0,56 \mathrm{a}$ & $1,78 \mathrm{a}$ & $2,33 \mathrm{a}$ & $2,67 \mathrm{a}$ & $3,22 \mathrm{a}$ \\
& $0 \mathrm{mg} . l^{-1}$ & $0,17 \mathrm{a}$ & $0,50 \mathrm{a}$ & $0,75 \mathrm{a}$ & $1,08 \mathrm{a}$ & $1,17 \mathrm{a}$ & $1,33 \mathrm{a}$ \\
Konsentrasi & $150 \mathrm{mg} . l^{-1}$ & $0,33 \mathrm{a}$ & $0,67 \mathrm{a}$ & $1,08 \mathrm{a}$ & $1,33 \mathrm{a}$ & $1,42 \mathrm{a}$ & $1,42 \mathrm{a}$ \\
IAA & $300 \mathrm{mg} . l^{-1}$ & $0,33 \mathrm{a}$ & $0,50 \mathrm{a}$ & $1,00 \mathrm{a}$ & $1,25 \mathrm{a}$ & $1,42 \mathrm{a}$ & $1,75 \mathrm{a}$ \\
& $450 \mathrm{mg} . l^{-1}$ & $0,42 \mathrm{a}$ & $0,50 \mathrm{a}$ & $0,83 \mathrm{a}$ & $1,17 \mathrm{a}$ & $1,33 \mathrm{a}$ & $1,67 \mathrm{a}$ \\
\hline
\end{tabular}

Keterangan: Angka yang diikuti notasi yang sama kolom yang sama menunjukkan berbeda tidak nyata menurut Uji Beda Nyata Terkecil (BNT) pada taraf 5\%; HST= hari setelah tanam

Berdasarkan percobaan mengenai efek IAA eksogen yang diberikan dengan berbagai konsentrasi, diduga IAA eksogen mampu berperan dalam pertumbuhan daun, buah, batang, dan akar. Namun, hasil penelitian ini ternyata tidak sepenuhnya sejalan dengan teori. hal ini sesuai dengan pendapat Isbiyantoro, Harwati, \& Sri (2013) yang menyatakan bahwa terdapat perbedaan yang besar antara efek auksin eksogen yang biasanya menghambat pemanjangan akar dengan efeknya yang memacu pertumbuhan dan perkembangan awal akar. Hal tersebut tentu saja berpengaruh terhadap pertumbuhan awal tunas. Walaupun demikian, akar beberapa spesies yang ditumbuhkan dalam biakan berhasil membentuk akar samping. Kejadian itu menunjukan bahwa dalam keadaan tersebut, akar tidak membutuhkan auksin atau akar sudah mempunyai cukup auksin (Salisbury \& Ross, 1995).

\section{Persen Tumbuh Tunas Bibit Bud Chip (\%)}

Berdasarkan data pengamatan dan hasil sidik ragam diketahui bahwa perlakuan sumber bud chip berpengaruh nyata terhadap persentase tumbuh tunas umur 1 MST, sedangkan perlakuan IAA dan interaksinya berpengaruh tidak nyata. Tabel 2 menunjukkan bahwa pada umur 1 MST persentase tumbuh tunas tertinggi yaitu bud chip yang berasal dari batang tengah dan berbeda nyata dengan bud chip yang berasal dari bagian atas dan bawah. Pengaruh nyata ini disebabkan oleh mata tunas yang berada pada batang tengah adalah mata tunas yang memiliki perbandingan asam amino dan karbohidrat yang seimbang (1:1) serta telah terbentuk sempurna sehingga dapat tumbuh dengan baik dan tidak mudah mati. Bagian pucuk tanaman tebu dibuang karena bagian ini kaya dengan kandungan asam amino tetapi miskin kandungan gula. Tebu bagian pangkal juga di buang karena kaya kandungan asam organis, gula reduksi, dan asam amino, akan tetapi miskin kandungan gula (Situmeang et al., 2015) 
Tabel 2. Persentase tumbuh bunas bibit bud chip pada 1 MST

\begin{tabular}{lcccccc}
\hline \multirow{2}{*}{$\begin{array}{c}\text { Sumber } \text { bud } \\
\text { chip }\end{array}$} & \multicolumn{4}{c}{ Konsentrasi IAA } & \multirow{2}{*}{ Total } & $\begin{array}{c}\text { Persentase } \\
(\%)\end{array}$ \\
\cline { 2 - 4 } & $0 \mathrm{mg} . l^{-1}$ & $150 \mathrm{mg} \cdot l^{-1}$ & $300 \mathrm{mg} \cdot l^{-1}$ & $450 \mathrm{mg} \cdot l^{-1}$ & & 6,00 \\
\hline Atas & 5,00 & 6,00 & 6,00 & 6,00 & 23,00 & $63,88 \mathrm{~b}$ \\
Tengah & 6,00 & 6,00 & 9,00 & 8,00 & 29,00 & $80,55 \mathrm{a}$ \\
Bawah & 5,00 & 5,00 & 6,00 & 5,00 & 21,00 & $58,33 \mathrm{~b}$ \\
\hline
\end{tabular}

Keterangan: Angka yang diikuti notasi yang sama kolom yang sama menunjukkan berbeda tidak nyata menurut Uji Beda Nyata Terkecil (BNT) pada taraf 5\%

Pada masing-masing bud chip yang ditanam juga diaplikasikan IAA pada berbagai macam konsentrasi namun IAA tersebut tidak berpengaruh banyak terhadap persentase tumbuh tunas, dengan demikian hal tersebut berkaitan dengan pertumbuhan awal akar. Pada awalnya IAA eksogen diperkirakan mampu berperan dalam pembentukan awal daun, batang dan akar. (Kuntoro, Sarwitri, \& Suprapto, 2016) menyatakan bahwa IAA biasanya menghambat pemanjangan akar, dengan efeknya yang memacu pertumbuhan dan perkembangan awal akar. Walaupun begitu, kemampuan akar untuk tumbuh dalam biakan selama beberapa minggu membuktikan bahwa akar tersebut tidak memerlukan auksin tambahan karena akar selalu memiliki kemampuan mensintesis auksin atau IAA dalam jumlah yang cukup bagi pertumbuhannya.

\section{Jumlah Daun Bibit Bud Chip}

Berdasarkan data pengamatan dan hasil sidik ragam diketahui bahwa perlakuan sumber bud chip berpengaruh nyata terhadap jumlah daun tebu, sedangkan perlakuan IAA dan interaksi keduanya berpengaruh tidak nyata (Tabel 3).

Tabel 3. Jumlah daun bibit bud chip (helai)

\begin{tabular}{ccccc}
\hline \multirow{2}{*}{ Perlakuan } & \multicolumn{3}{c}{ Waktu pengamatan } \\
\cline { 3 - 5 } & & $2 \mathrm{MST}$ & $6 \mathrm{MST}$ & $10 \mathrm{MST}$ \\
\hline \multirow{2}{*}{$\begin{array}{c}\text { Sumber Bud } \\
\text { chip }\end{array}$} & Atas & $2,67 \mathrm{~b}$ & $3,44 \mathrm{a}$ & $4,11 \mathrm{~b}$ \\
& Tengah & $3,00 \mathrm{a}$ & $3,67 \mathrm{a}$ & $5,00 \mathrm{a}$ \\
& Bawah & $2,67 \mathrm{~b}$ & $3,33 \mathrm{a}$ & $4,22 \mathrm{~b}$ \\
\hline \multirow{2}{*}{ Konsentrasi } & $0 \mathrm{mg} . l^{-1}$ & $1,50 \mathrm{a}$ & $1,83 \mathrm{a}$ & $2,50 \mathrm{a}$ \\
IAA & $150 \mathrm{mg} . l^{-1}$ & $1,50 \mathrm{a}$ & $1,83 \mathrm{a}$ & $2,58 \mathrm{a}$ \\
& $300 \mathrm{mg} . l^{-1}$ & $1,58 \mathrm{a}$ & $2,08 \mathrm{a}$ & $2,50 \mathrm{a}$ \\
& $450 \mathrm{mg} . l^{-1}$ & $1,67 \mathrm{a}$ & $2,08 \mathrm{a}$ & $2,42 \mathrm{a}$ \\
\hline
\end{tabular}

Keterangan: Angka yang diikuti notasi yang sama kolom yang sama menunjukkan berbeda tidak nyata menurut Uji Beda Nyata Terkecil (BNT) pada taraf 5\%; MST = minggu setelah tanam

Tabel 3 menunjukkan bahwa tanaman dengan jumlah daun terbanyak adalah perlakuan sumber bud chip yang berasal dari batang tengah dan berbeda nyata dengan bud chip yang berasal dari batang atas dan bawah. Mata tunas yang terdapat pada batang tengah adalah mata tunas yang terbentuk sempurna dan pertumbuhannya baik sehingga kandungan karbohidrat yang terdapat pada 
batang tengah juga memiliki kandungan yang lebih tinggi dibanding batang atas dan bawah (Situmeang et al., 2015).

Aplikasi IAA pada berbagai sumber bud chip memperlihatkan bahwa tidak terjadi respons positif dari berbagai sumber bud chip tersebut sehingga tidak menghasilkan pengaruh yang signifikan pada pembentukan daun tanaman tebu. Hal ini terkait dengan fungsi kebanyakan auksin yang lebih berpengaruh pada pembentukan awal akar (Salisbury \& Ross, 1995).

\section{Tinggi Tanaman Bibit Bud Chip}

Berdasarkan data pengamatan dan hasil sidik ragam diketahui bahwa perlakuan sumber bud chip berpengaruh nyata terhadap tinggi tanaman tebu sedangkan perlakuan IAA dan interaksi keduanya berpengaruh tidak nyata (Tabel 4).

Tabel 4. Tinggi tanaman bibit bud chip $(\mathrm{cm})$

\begin{tabular}{ccccc}
\hline \multirow{2}{*}{ Perlakuan } & \multicolumn{3}{c}{ Waktu pengamatan } \\
\cline { 2 - 5 } & Atas & $2 \mathrm{MST}$ & $6 \mathrm{MST}$ & $10 \mathrm{MST}$ \\
\hline \multirow{2}{*}{$\begin{array}{c}\text { Sumber } \text { Bud } \\
\text { chip }\end{array}$} & Tengah & $2,67 \mathrm{~b}$ & $3,44 \mathrm{a}$ & $4,11 \mathrm{~b}$ \\
& Bawah & $3,00 \mathrm{a}$ & $3,67 \mathrm{a}$ & $5,00 \mathrm{a}$ \\
\hline \multirow{2}{*}{ Konsentrasi } & $0 \mathrm{mg} . l^{-1}$ & $2,67 \mathrm{~b}$ & $3,33 \mathrm{a}$ & $4,22 \mathrm{~b}$ \\
\multirow{2}{*}{ IAA } & $150 \mathrm{mg} . l^{-1}$ & $1,50 \mathrm{a}$ & $1,83 \mathrm{a}$ & $2,50 \mathrm{a}$ \\
& $300 \mathrm{mg} . l^{-1}$ & $1,50 \mathrm{a}$ & $1,83 \mathrm{a}$ & $2,58 \mathrm{a}$ \\
& $450 \mathrm{mg} . l^{-1}$ & $1,58 \mathrm{a}$ & $2,08 \mathrm{a}$ & $2,50 \mathrm{a}$ \\
\end{tabular}

Keterangan: Angka yang diikuti notasi yang sama kolom yang sama menunjukkan berbeda tidak nyata menurut Uji Beda Nyata Terkecil $(\mathrm{BNT})$ pada taraf $5 \%$; MST = minggu setelah tanam

Tabel 4 menunjukkan bahwa tanaman tertinggi dihasilkan oleh perlakuan sumber bud chip yang berasal dari batang tengah karena pada mata tunas yang berasal batang tengah memiliki perbandingan asam amino dan karbohidrat yang seimbang (1:1) serta telah terbentuk sempurna (Situmeang et al., 2015). Proses siklus pertumbuhan tanaman terdiri atas dua fase, yaitu fase pembelahan dan fase pelebaran sel. Pada saat sel mengalami fase pembesaran, sel tidak hanya mengalami peregangan, akan tetapi juga mengalami penebalan dalam pembentukan materialmaterial dinding sel baru (Riski, Rahayu, \& Adimihardja, 2019). Oleh karena itu mata tunas yang terdapat pada batang tengah dapat melalui fase pembelahan dan pelebaran sel dengan baik sehingga memiliki pertumbuhan paling baik diantara mata tunas dari batang atas dan bawah. Hal ini diduga karena mata tunas yang berasal dari batang tengah ialah mata tunas yang terbentuk sempurna sehingga pertumbuhannya baik dan kandungan karbohidrat yang terdapat pada batang tengah juga memiliki kandungan yang lebih tinggi. Setek yang mengandung karbohidrat yang tinggi akan mempermudah pembentukan akar sehingga setek dapat tumbuh dengan baik. Pada batang yang 
berasal dari bagian tengah memiliki kandungan karbohidrat yang tinggi dibandingkan dengan batang atas (Wijayanti, Thamrin, \& Sumarni, 2017)

Aplikasi IAA pada beberapa sumber bud chip tidak memberikan pengaruh yang signifikan pada pertumbuhan tinggi batang tebu umur 0-10 MST. Hal tersebut sesuai dengan pernyataan Alpriyan \& Karyawati (2019) dimana fase pertumbuhan, pemanjangan, dan pembesaran batang terjadi pada umur tebu antara 3-9 bulan yang terkait dengan perubahan fisik tanaman yang berlangsung cepat.

\section{Diameter Pelepah Bibit Bud Chip}

Berdasarkan data pengamatan dan hasil sidik ragam diketahui bahwa perlakuan sumber bud chip berpengaruh nyata terhadap diameter pelepah tebu, sedangkan perlakuan IAA dan interaksinya berpengaruh tidak nyata (Tabel 5). Keseimbangan antara asam amino dan karbohidrat yang seimbang pada batang tengah berperan penting terhadap pertumbuhan diameter pelepah yang baik. Hal ini didukung oleh Wijayanti et al. (2017) yang menyatakan bahwa kemampuan setek membentuk akar dan tunas dipengaruhi oleh kandungan karbohidrat dan keseimbangan hormon.

Tabel 5. Diameter pelepah bibit bud chip (mm)

\begin{tabular}{ccccc}
\hline \multirow{2}{*}{ Perlakuan } & & \multicolumn{3}{c}{ Waktu pengamatan } \\
\cline { 2 - 5 } Sumber Bud & Atas & $2 \mathrm{MST}$ & $6 \mathrm{MST}$ & $10 \mathrm{MST}$ \\
\hline \multirow{2}{*}{ chip } & Tengah & $3,21 \mathrm{~b}$ & $3,95 \mathrm{~b}$ & $4,37 \mathrm{~b}$ \\
& Bawah & $3,42 \mathrm{a}$ & $4,00 \mathrm{a}$ & $4,51 \mathrm{a}$ \\
\multirow{3}{*}{ Konsentrasi IAA } & $3,28 \mathrm{~b}$ & $3,95 \mathrm{~b}$ & $4,41 \mathrm{~b}$ \\
& $0 \mathrm{mg} \cdot l^{-1}$ & $1,81 \mathrm{a}$ & $2,20 \mathrm{a}$ & $2,44 \mathrm{a}$ \\
& $150 \mathrm{mg} \cdot l^{-1}$ & $1,88 \mathrm{a}$ & $2,24 \mathrm{a}$ & $2,50 \mathrm{a}$ \\
& $300 \mathrm{mg} \cdot l^{-1}$ & $1,87 \mathrm{a}$ & $2,24 \mathrm{a}$ & $2,51 \mathrm{a}$ \\
& $450 \mathrm{mg} \cdot l^{-1}$ & $1,88 \mathrm{a}$ & $2,28 \mathrm{a}$ & $2,52 \mathrm{a}$ \\
\hline
\end{tabular}

Keterangan: Angka yang diikuti notasi yang sama kolom yang sama menunjukkan berbeda tidak nyata menurut Uji Beda Nyata Terkecil (BNT) pada taraf 5\%; MST = minggu setelah tanam

Aplikasi IAA dengan berbagai konsentrasi yang diharapkan mampu merangsang diameter pelepah agar lebih cepat pertumbuhannya justru tidak memilik pengaruh yang signifikan, dimana pada dasarnya fase pertumbuhan, pemanjangan dan pembesaran batang terjadi pada umur tebu antar 3-9 bulan, hal ini terkait dengan perubahan fisik tanaman yang terjadi begitu cepat (Alpriyan \& Karyawati, 2019). Maka dari itu sewajarnya pertumbuhan diameter batang tebu terjadi setelah fase pertunasan yaitu pada fase pemanjangan dan pembesaran batang yang berlangsung sekitar 120-150 hari setelah tanam. Dibutuhkan juga kondisi lingkungan yang optimal seperti air, pupuk, suhu udara, dan sinar matahari. 


\section{KESIMPULAN}

Berdasarkan hasil penelitian dapat disimpulkan bahwa asal bibit bud chip bagian tengah menghasilkan pertumbuhan terbaik yang ditunjukkan oleh variabel kecepatan tumbuh, persentase tumbuh, tinggi bibit, jumlah daun, dan diameter pelepah. Pemberian IAA pada konsentrasi $0-450$ mg. $l^{1}$ yang telah diterapkan pada sumber bud chip bagian atas, tengah, dan bawah dengan perlakuan perendaman selama 20 menit tidak berpengaruh nyata pada variabel kecepatan tumbuh, persentase tumbuh, tinggi bibit, jumlah daun, dan diameter pelepah. Tidak terdapat interaksi antara perlakuan asal bibit bud chip dan konsentrasi IAA.

\section{DAFTAR PUSTAKA}

Adinugraha, I., Nugroho, A., \& Wicaksono, K. P. (2016). Pengaruh asal bibit bud chip terhadap fase vegetatif tiga varietas tanaman tebu (Saccharum officinarum L.). Jurnal Produksi Tanaman, 4(6), 468-477.

Alpriyan, D., \& Karyawati, A. S. (2019). Pengaruh konsentrasi dan lama perendaman hormon auksin pada bibit tebu (Saccharum officinarum L.) teknik bud chip. Jurnal Produksi Tanaman, 6(7), 1354-1362.

Badan Pusat Statistik. (2017). Produksi tanaman perkebunan. Retrieved August 7, 2018, from Badan Pusat Statistik website: https://www.bps.go.id

Brilliyana, Y. M., Sumiya, W., Yamika, D., \& Wicaksono, P. (2017). Pengaruh berbagai media tanam terhadap pembibitan bud chip tanaman tebu (Saccharum officinarum L.) varietas BL. Jurnal Produksi Tanaman, 5(2), 355-362.

Dezjona, P. A., Sudiarso, \& Islami, T. (2013). Pengaruh komposisi media tanam pada teknik bud chip tiga varietas tebu (Saccharum officinarum L .). Jurnal Produksi Tanaman, 1(1), 16-23.

Indrawanto, Purwono, C., Siswanto, Syakir, M., \& Rumini, W. (2010). Budidaya dan Pasca Panen Tebu. Eska Media: Jakarta.

Isbiyantoro, D., Harwati, T., \& Sri, H. (2013). Pengaruh konsentrasi zat pengatur tumbuh (IAA, Root Up, dan Gibgro-20T ) terhadap pertumbuhan jahe ( Zingiber officinale Rosc.). Journal of Chemical Information and Modeling, 53(9), 1689-1699. https://doi.org/10.1017/CBO9781107415324.004

Iwan, I., Bambang, S., \& Ubud, B. (2014). Pengaruh konsentrasi dan lama perendaman Rootone-F terhadap pertumbuhan stek tebu (Sacharum officinarum L.). Jurnal Produksi Tanaman, 3(4), $1-12$.

Kuntoro, D., Sarwitri, R., \& Suprapto, A. (2016). Pengaruh macam auksin pada pembibitan beberapa varietas tanaman jati (Tectona grandis, L.). Jurnal Ilmu Pertanian Tropika dan Subtropika, 1(1), 7-11.

Riski, K., Rahayu, A., \& Adimihardja, S. (2019). Pengaruh berbagai konsentrasi IBA dan urin sapi terhadap pertumbuhan setek tanaman lada (Piper nigrum L.). Journal of Chemical Information and Modeling, 53(9), 1689-1699. https://doi.org/10.1017/CBO9781107415324.004. 
Salisbury, F., \& Ross, C. (1995). Fisiologi Tumbuhan Jilid 3. Bandung: ITB.

Selvia, I., Meiriani, M., \& Hasanah, Y. (2015). Keragaan bibit bud chips tebu (Saccharum officinarum L.) dengan perlakuan lama perendaman dan konsentrasi IAA. Agroekoteknologi, 3(2), 489-498.

Situmeang, H. P., Barus, A., \& Irsal. (2015). Pengaruh konsentrasi zat pengatur tumbuh dan sumber bud chips terhadap pertumbuhan bibit tebu (Saccharum officinarum L.) di pottray. Agroekoteknologi, 3(3), 992-1004.

Wijayanti, M. R., Thamrin, H., \& Sumarni, T. (2017). Pengaruh perendaman air panas pada batang atas, tengah dan bawah terhadap pertumbuhan bud chip tebu (Saccharum officinarum L.) varietas Bululawang. Jurnal Produksi Pertanian, 5(9), 1432-1439.

Yulianingtyas, A. P., Sebayang, H. T., \& Tyasmoro, S. Y. (2015). Pengaruh komposisi media tanam dan ukuran bibit pada pertumbuhan pembibitan tebu (Saccharum officinarum L.). Jurnal Produksi Tanaman, 3(5), 362-369. 